\title{
Correlation between classes of mating events in two experimental plant populations
}

\author{
D. J. Schoen
}

\begin{abstract}
Department of Biology, McGill University, 1205 Ave. Docteur Penfield, Montreal, Quebec H3A 1B1 Canada.
\end{abstract}

\begin{abstract}
When maternal parent and progeny genotypes are known, inferences can be drawn about the paternal contribution to the mating event. A mating event is defined here as the fertilisation of an egg. With a diallelic locus and homozygous seed parent, mating events may be classified as detected outcrosses or as ambiguous mating events (those due to either self-fertilisation or outcrossing). When mating events are classified and when seed are sampled at two or more hierarchical levels within populations (e.g., seeds within fruits, fruits within plants) one may estimate the degree of correlation between classes of mating events at a given hierarchical level relative to that at others. Such an analysis applied to progeny from an experimental population of the common morning glory shows that there is correlation between classes of mating events within fruits, but not between fruits. In an experimental population of white spruce, the analysis reveals a low degree of correlation between classes of mating events both within and between cones. The results are discussed in relation to the pollination systems of the plants and to the problem of estimating genetic parameters from family-structured data.
\end{abstract}

\section{INTRODUCTION}

Among the ways in which to characterise the mating system of plants, the estimation of the proportion of ovules which are outcrossed or selfpollinated has played a prominent role (Fyfe and Bailey, 1951; Brown and Allard, 1970; Clegg, Kahler, and Allard, 1978; Shaw, Kahler, and Allard, 1981; Ritland and Jain, 1981; Schoen and Clegg, 1984). The outcrossing rate, however, provides only a portion of the information required to fully describe the pattern of gene transmission in plant populations. Other approaches have focused on the estimation of effective rate of self-fertilisation when populations are inbred (Ritland, 1984), the relative contributions of male and female gametes by different parental genotypes to the progeny generation (Harding and Tucker, 1969; Clegg et al., 1978; Müller-Starck, 1982), and the number of pollen parents siring a family of seed (Ellstrand, 1984).

Yet another analytical perspective on the mating systems of plant populations can be achieved by considering the relationship among classes of mating events. A mating event is defined here as the fertilisation of an egg. With a diallelic marker locus and homozygous seed parent $\left(A_{i} A_{i}\right)$, there are two distinguishable classes of mating events:
(1) a detected outcross class ( $A_{i} A_{j}$ progeny); and (2) an ambiguous class ( $A_{i} A_{i}$ progeny), so-called due to its possible origin by either self-fertilisation or outcrossing. When seeds are sampled at two or more hierarchical levels of organisation (e.g., seeds within fruits, fruits within plants, etc.) one may estimate the degree of correlation between classes of mating events at a given hierarchical level relative to that at others. Such an analysis parallels that of the genetical structure of populations (Wright, 1951; Cockerham, 1969; 1973). It may be useful in validating assumptions concerning the degree of covariance among progeny within a group, which when violated can lead to biased estimates of heritability (Falconer, 1960; Squillace, 1974). It may also be helpful in choosing the most appropriate model for the estimation of mating system parameters. Schoen and Clegg (1984) showed if there is correlation between mating events within families, application of the mixed mating model to family-structured data can lead to biased estimates of the outcrossing rate and pollen pool allele frequencies. In such cases, an alternative estimation procedure, based on the one pollen parent modification of the mixed mating model, may be more appropriate (Schoen and Clegg, 1984). 
This paper reports the results of a study of correlation between classes of mating events at the within fruit (cone) and within plant levels in populations of the common morning glory, Ipomoea purpurea (Convolvulaceae), and white spruce, Picea glauca (Pinaceae).

\section{MATERIALS AND METHODS}

\section{(i) Common morning glory}

The plants studied originated from a population which is polymorphic at a locus coding for the distribution of pigmentation within flowers. The genotype $W / W$ codes for darkly pigmented petals, $W / w$ for lightly pigmented petals, and $w / w$ for white petals (Ennos and Clegg, 1983). Seed families were obtained as part of an experiment which was also designed to investigate the influence of the pigmented and white flower colour polymorphism on outcrossing rate and male gametic contribution (Schoen and Clegg, 1985). The experiment was conducted in a field plot adjacent to the University of Georgia greenhouses in Athens, Georgia, USA. The plot is accessible to native bumblebees; during two days of the experiment when pollinator visits were monitored, each flower was visited two or more times (Schoen and Clegg, 1985). On the evening preceeding each of 19 days in July and August of 1983, 24 plants, trimmed so as to bear the same number of flowers (usually two or three), were moved for the day from the greenhouse to the adjacent field plot. As is typical for members of this genus, flowers were closed in the evening at the time of their transport into the field, open the following day, and wilted by the afternoon of the same day. The field plot comprised 24 positions, arranged as a rectangular $6 \times 4$ grid, with one metre spacing between adjacent positions. Equal numbers of plants with white and darkly pigmented petals were randomly assigned positions in the grid. These plants were also polymorphic at a locus coding for esterase (E.C.3.1.1.1) (Ennos and Clegg, 1983). In design 1 (11 out of 19 days), the twelve white-flowered plants were homozygous for the fast-migrating esterase allele $\left(E s t^{F}\right)$, while six of the pigmented-flowered plants were homozygous for the slow-migrating esterase allele $\left(E s t^{s}\right)$, and six were heterozygous. In design 2 ( 8 days), the twelve pigmented-flowered plants were homozygous for Est ${ }^{s}$, while six of the whiteflowered plants were homozygous for $E s t^{F}$, and six were heterozygous. Seeds were collected from plants 3 weeks after flowering and were kept separ- ate by fruit, maternal parent, and treatment. Electrophoresis was conducted using extracts of 14 day old seedlings. Seedling germination and electrophoretic methods are described elsewhere (Schoen, et al., 1984; Ennos and Clegg, 1983).

\section{(ii) White spruce}

The trees sampled formed part of a clonal seed orchard maintained by the Ontario Ministry of Natural Resources. The orchard is located in Glencairn, Ontario, Canada. Each block contains up to twelve ramets of twelve different clonally propagated trees, with the ramets planted in random positions in the block. Through the electrophoretic analysis of leaf tissue extracts, genotypes of five clones (in two blocks) were determined at loci coding for phosphoglucomutase (E.C.2.7.5.1) and glutamate dehydrogenase (E.C.1.4.1.3). These loci are abbreviated below as $P g m$ and $G d h$, respectively. Viable seeds from each of two female cones per ramet, and from two or more ramets per clone were sampled. Seeds were germinated and dissected to separate the megagametophyte and embryo. Extracts from the two tissues were run side by side on the gels. This procedure allows identification of the paternal contribution to the embryo genotype. Electrophoretic methods followed those of Cheliak and Pitel (1984).

\section{RESULTS}

\section{(i) Common morning glory}

The distribution of detected outcrossing events and ambiguous mating events was examined through analysis of variance. Following Cockerham (1969; 1973), an indicator viable, $X_{i j k l}$, indexing the $i$ th seed of the $j$ th fruit of the $k$ th plant of the $l$ th maternal parent class was assigned a value of 0 (ambiguous mating event) or 1 (detected outcross). There were 2-6 seeds per fruit, 1-11 fruits per plant, 16-25 plants per maternal class, and 4 maternal classes (corresponding to the $W / W, E_{s t}{ }^{F} / E_{s t}{ }^{F}$ and $w / w, E s t^{s} / E s t^{s}$ double homozygotes from designs 1 and 2) for a total of $N=1128$ seed genotypes at the Est locus. A nested design analysis of variance partitioned the effects of the different levels. This is a mixed model nested analysis of variance; the highest hierarchical level (maternal classes) is a fixed treatment, while the remaining levels (plants and fruits) are random effects (Sokal and Rohlf, 1981). Significant variation was detected at the between maternal class and between fruit 
Table 1 Analysis of variance of mating events in an experimental population of Ipomoea purpurea*

\begin{tabular}{|c|c|c|c|c|c|}
\hline Source & df & SS & MS & $\mathrm{F}_{\mathrm{s}}{ }^{\dagger}$ & $\begin{array}{l}\text { Variance } \\
\text { component }\end{array}$ \\
\hline $\begin{array}{l}\text { Among } \\
\text { maternal } \\
\text { classes }\end{array}$ & 3 & $12 \cdot 734$ & $4 \cdot 248$ & $12.620 \ddagger$ & - \\
\hline $\begin{array}{l}\text { Among } \\
\text { plants }\end{array}$ & 83 & $27 \cdot 859$ & 0.336 & 1.021 & 0.000 \\
\hline $\begin{array}{l}\text { Among } \\
\text { fruits }\end{array}$ & 216 & $75 \cdot 135$ & 0.348 & $2 \cdot 100 \ddagger$ & 0.050 \\
\hline Error & 825 & $136 \cdot 583$ & $0 \cdot 166$ & & $0 \cdot 166$ \\
\hline
\end{tabular}

* Analysis based on $X_{i j k l}$ (see text)

$\dagger$ Satterthwaite approximation (Sokal and Rohlf, 1981) used in the calculation of $\mathrm{F}_{\mathrm{s}}=\mathrm{MS}_{\mathrm{fruits}} / \mathrm{MS}_{\text {error }}$ and $\mathrm{F}_{\mathrm{s}}=$ $\mathrm{MS}_{\text {plants }} / \mathrm{MS}_{\text {fruits }}$

$\ddagger P<0.001$

levels (table 1). The within fruit component of variance $\left(s_{w}{ }^{2}\right)$, the between fruit within plant component $\left(s_{b}^{2}\right)$, and the between plant within maternal class component $\left(s_{a}^{2}\right)$ were used to estimate the intra-class correlation between frequencies of mating events of different fruits in the same plant, $r_{a}=s_{a}{ }^{2} /\left(s_{w}{ }^{2}+s_{b}{ }^{2}+s_{a}^{2}\right)$, of mating events within random fruits from different plants, $r_{a b}=$ $\left(s_{a}{ }^{2}+s_{b}{ }^{2}\right) /\left(s_{w}{ }^{2}+s_{b}{ }^{2}+s_{a}{ }^{2}\right)$, and of mating events within fruits within plants, $r_{b}=s_{b}{ }^{2} /\left(s_{w}{ }^{2}+s_{b}{ }^{2}\right)$. Values of $r_{a}, r_{a b}$, and $r_{b}$ are $0,0.232$, and 0.232 , respectively. The analysis of variance and intraclass correlations therefore indicate that mating events are more highly correlated within than between fruits.

\section{(ii) White spruce}

The indicator variable, $X_{i j k l}$, for these data, indexes the $i$ th seed of the $j$ th cone of the $k$ th ramet of the $l$ th clone. It was assigned a value of 0 or 1 as above.

For Pgm, there were $12-77$ seeds per cone, two cones per ramet, $2-3$ ramets per clone, and 4 clones for a total of $N=906$ seed genotypes. The analysis of variance is again a mixed model, with clones as the fixed treatment. Significant variation was detected only between clones (table 2 ). The values of $r_{a}, r_{a b}$, and $r_{b}$, calculated as above, are all 0 .

For $G d h$, there were $12-94$ seeds per cone, two cones per ramet, 2-3 ramets per clone, and five clones, for a total of $N=1067$ seed genotypes. Significant variation was again detected only at the between clone level (table 3 ). The values of $r_{a}, r_{a b}$, and $r_{b}$ are $0,0.009$, and 0.009 , respectively. The analyses of variance and intra-class correlations for white spruce therefore suggest that there is little
Table 2 Analysis of variance of mating events in a clonal seed orchard of Picea glauca (Pgm marker locus)*

\begin{tabular}{lrrrrl}
\hline Source & df & SS & MS & $\mathrm{F}_{\mathrm{s}}^{\dagger}$ & $\begin{array}{l}\text { Variance } \\
\text { component }\end{array}$ \\
\hline $\begin{array}{l}\text { Among } \\
\text { clones }\end{array}$ & 3 & 23.149 & 7.716 & $53.395 \ddagger$ & - \\
$\begin{array}{l}\text { Among } \\
\text { ramets }\end{array}$ & 6 & 0.876 & 0.146 & 0.920 & 0.000 \\
$\begin{array}{l}\text { Among } \\
\text { cones }\end{array}$ & 10 & 1.610 & 0.161 & 0.763 & 0.000 \\
\begin{tabular}{l} 
Error \\
\hline
\end{tabular} & 886 & 187.020 & 0.211 & & 0.211 \\
\hline
\end{tabular}

* Analysis based on $X_{i j k l}$ (see text)

† Satterthwaite approximation (Sokal and Rohlf, 1981) used in the calculation of $\mathrm{F}_{\mathrm{s}}=\mathrm{MS}_{\text {cones }} / \mathrm{MS}_{\text {error }}$ and $\mathrm{F}_{\mathrm{s}}=$ $\mathrm{MS}_{\text {ramets }} / \mathrm{MS}_{\text {cones }}$

$\ddagger P<0.001$

Table 3 Analysis of variance of mating events in a clonal seed orchard of Picea glauca ( $\mathrm{Gdh}$ marker locus)*

\begin{tabular}{lrrrrl}
\hline Source & df & SS & MS & $\mathrm{F}_{s} \dagger$ & $\begin{array}{l}\text { Variance } \\
\text { component }\end{array}$ \\
\hline $\begin{array}{l}\text { Among } \\
\text { clones }\end{array}$ & 4 & 17.007 & 4.252 & $7.896 \ddagger$ & - \\
$\begin{array}{l}\text { Among } \\
\text { ramets }\end{array}$ & 7 & 3.559 & 0.509 & 1.766 & 0.000 \\
$\begin{array}{l}\text { Among } \\
\text { cones }\end{array}$ & 12 & 3.433 & 0.286 & 1.300 & 0.002 \\
Error & 1043 & 229.367 & 0.220 & & 0.220 \\
\hline
\end{tabular}

* Analysis based on $X_{i j k l}$ (see text)

† Satterthwaite approximation (Sokal and Rohlf, 1981) used in the calculation of $\mathrm{F}_{\mathrm{s}}=\mathrm{MS}_{\text {cones }} / \mathrm{MS}_{\text {error }}$ and $\mathrm{F}_{\mathrm{s}}=$ $\mathrm{MS}_{\text {ramets }} / \mathrm{MS}_{\text {cones }}$

$\ddagger P<0.05$

difference in degree of correlation between mating events within or between cones in the seed orchard.

\section{DISCUSSION}

The higher degree of correlation between classes of mating events occurring at the within fruit (cone) level in morning glory compared with white spruce can be attributed to two factors: (1) greater variation between flowers of morning glory in the rate of outcrossing than between cones of white spruce (perhaps brought about by variable climatic conditions for insect-mediated pollination or by variable floral morphology); and (2) greater variation in the genetic composition of pollen sampled by individual flowers of morning glory than by cones of white spruce. The present experiments 
are unable to distinguish between these two possible causes. Pollinator visitation rates were high during both overcast and sunny weather periods (Schoen, unpublished), and there was little apparent morphological variation between flowers. It is likely, therefore, that the first factor, variation in outcrossing rates between flowers, contributed less strongly to the observed correlation between classes of mating events. Variation in the genetic composition of pollen desposited on the stigmas of different flowers may, therefore, be primarily responsible for the result. Such variation could exist if pollen deposited on the stigma derives from only one or a few different donors in the population.

In white spruce, the apparent lack of correlation between classes of mating events at the cone level suggests only minimal variation between cones in both their outcrossing rates and sampling of pollen genotypes. This supports the notion that wind-pollination allows more mixing of pollen than insect-pollination, where pollen is presumably transported between flowers in more discrete clumps.

Neither population exhibited variation in frequencies of detected outcrosses at the between plant (ramet) level. For morning glory this suggests that individual plants do not differ in their rate of outcrossing, a conclusion which concords with the above interpretation of the among flower variation. It also suggests that the daily randomising of plants in the $6 \times 4$ grid was effective in removing any spatial effect of local differentiation in pollen pool allele frequencies. In the case of white spruce, the fixed spatial positions of the ramets apparently do not lead to strong local sampling of the pollen pool, a result which may also be attributable to pollen mixing in wind-pollination.

At the between maternal genotype (clone) level, the analyses demonstrate significant variation in the frequency of detected outcrosses in populations of both species. The finding is not surprising given other findings which demonstrate or suggest outcrossing rate heterogeneity among plants within populations (Adams and Joly, 1980; Ennos, 1981; Brown and Clegg, 1985).

Several other implications of the results are worthy of mention, as they illustrate the potential usefulness of the above-described analysis. First, in the case of morning glory, seed families assembled from one or a few fruits are likely to be characterised by average genetic correlations among offspring significantly greater than the value of 0.25 expected when assuming half-sib families. Both self-fertilisation as well as the occurrence of full-sibs (from outcrossing events sharing the same paternal parent) may be responsible for the higher level of average genetic correlation between offspring within such families. In this instance, the assumption of half-sibs would result in an overestimate of heritability and genetic gain (Squillace, 1974). Second, mating system estimation based on the mixed mating model, a procedure which assumes independence between mating events within families, should be applied with caution to families assembled from few fruits in morning glory. This conclusion concurs with results from Ennos' (1981) study of Ipomoea purpurea and I. hederacea, where the mixed mating model failed to fit the data due to an excess of heterozygote progeny in families of heterozygote seed parents. Such deviations are also observed when mating system estimation is carried out with family-structured data produced via Monte Carlo simulations in which mating events are correlated within families (Schoen and Clegg, 1984). A third implication of the results pertains to the objectives of conifer seed orchards (Woessner and Franklin, 1973). The absence of detectable between ramet variation in the frequencies of detected outcrosses suggests a low level of differentiation in the pollen pools sampled by different ramets (i.e., ramets are exposed to the pollen of more than their immediate neighbours). Extreme local mating is, therefore, not occurring within the orchard. This is desirable, since conifer seed orchards are designed to foster maximum mixing of gametes from separate clones.

Acknowledgements I thank Dr Michael T. Clegg for his advice and assistance throughout this project, Drs Bryan Epperson, Kermit Ritland, and Steven Stewart, for their comments on earlier versions of the manuscript, and Ms Cremilda Dias for her careful technical assistance. This research was supported by National Science Foundation grant BSR-8304796 to Dr M. T. Clegg and by Natural Sciences and Engineering Research Council of Canada Operating and Strategic Grants to the author.

\section{REFERENCES}

ADAMS, W. T. AND JOLY, R. J. 1980. Allozyme studies in loblolly pine seed orchards: clonal variation and frequencies of progeny due to self-fertilisation. Silvae Genet, 29, 1-4.

BROWN, A. H. D. AND ALLARD, R. W. 1970. Estimation of mating system in open-pollinated maize populations using isozyme polymorphisms. Genetics, 66, 133-145.

BROWN, B. A. AND CLEGG, M. T. 1985. Influence of flower color polymorphism on genetic transmission in a natural population of the common morning glory, Ipomoea purpurea. Evolution, 38, 796-803.

CHELIAK, W. M. AND PITEL, J. A. 1984. Genetic control of allozyme variants in mature tissues of white spruce trees. J. Hered., 75, 34-40. 
CLEGG, M. T., KAHLER, A. L. AND ALLARD, R. W. 1978. Estimation of life cycle components of selection in an experimental plant population. Genetics, 89, 765-792.

COCKERHAM, C. C. 1969. Variance of gene frequencies. Evolution, 23, 72-84.

COCKERHAM, C. C. 1973. Analyses of gene frequencies. Genetics, 74, 696-700.

ELLSTRAND, N. C. 1984. Multiple paternity within the fruits of the wild radish. Amer. Natur., 123, 819-828.

ENNOS, R. A. 1981. Quantitative studies of the mating system in two sympatric populations of Ipomoea (Convolvulaceae). Genetica, 57, 93-98.

ENNOS, R. A. AND CLEGG, M. T. 1982. Effects of population substructuring on estimates of outcrossing rate in plant populations. Heredity, 48, 282-293.

FALCONER, D. S. 1960. Introduction to Quantitative Genetics. Ronald Press, New York.

FYFE, J. L. AND BAILEY, N. T. J. 1951. Plant breeding studies in leguminous forage crops. 1. Natural cross-breeding in winter beans. J. Agric. Sci., 41, 371-378.

HARDING, J. AND TUCKER, C. L. 1969. Quantitative studies on mating systems. III. Methods for the estimation of male gametophytic selective value and differential outcrossing rates. Evolution, 23, 85-95.

MULLER-STARCK, G. 1982. Reproductive systems in conifer seed orchards. 1. Mating probabilities in a seed orchard of Pinus sylvestris L. Silvae Genet., 31, 188-197.

RitLAND, K. 1984. The effective proportion of self-fertilization with consanguinous matings in inbred populations. Genetics, 106, 139-152.
RitLAND, K. AND JAIN, S. K. 1981. A model for the estimation of outcrossing rate and gene frequencies using $n$ independent loci. Heredity, 47, 35-52.

SCHAAL, B. A. 1980. Measurement of gene flow in Lupinus texensis. Nature, 284, 450-451.

SCHOEN, D. J., GIANNASI, D. E., ENNOS, R. A. AND CLEGG, M. T. 1984. Stem color and pleiotropy of genes determining flower color in the common morning glory. J. Hered., 75 , 113-116.

SCHOEN, D. J. AND CLEGG, M. T. 1984. Estimation of mating system parameters when outcrossing events are correlated. Proc. Natl. Acad. Sci., U.S.A., 81, 5258-5262.

SCHOEN, D. J. AND CLEGG, M. T. 1985. The influence of flower color on outcrossing rate and male reproductive success in Ipomoea purpurea. Evolution (in press).

SHAW, D. V., KAHLER, A. L. AND ALLARD, R. W. 1981. A multilocus estimator of mating system parameters in plant populations. Proc. Natl. Acad. Sci., U.S.A., 78, 1298-1302.

SOKAL, R. R. AND ROHLF, F. J. 1981. Biometry, W. H. Freeman, San Francisco.

SQUILLACE, A. E. 1974. Average genetic correlations among offspring from open-pollinated forest trees. Silvae Genet., $23,149-155$.

WOESSNER, R. A. AND FRANKLIN, E. C. 1973. Continued reliance on wind-pollinated southern pine seed orchards, is it reasonable? Proc. 12th Southern Forest Tree Improve. Conf., 64-73.

WRIGHT, S. 1951. The genetical structure of populations. Ann. Eugen., 15, 323-354. 